\title{
N87-29935
}

\section{POLYPHASE ALLOYS AS RECHARGEABLE ELECTRODES IN ADVANCED BATTERY SYSTEMS}

\author{
Robert A. Huggins \\ Stanford University \\ Stanford, California 94305
}

The rechargeability of electrochemical cells is often limited by negative electrode problems. These may include loss of capacity, increased impedance (which may be observed as reduced cell voltage upon discharge, and increased overvoltage upon recharge), macroscopic shape change, dendrite growth, or a tendency for filamentary or whisker growth.

In principle, these problems can be reduced or eliminated by the use of alloys that undergo either displacement or insertion reactions at reactant species activities less than unity, rather than pure elements. On the other hand, this approach always involves some sacrifice of cell voltage and a reduced specific energy.

The fundamental reasons for some of these problems with elemental electrodes, as well as the basic principles involved in the different behavior of alloys, will be briefly discussed.

A considerable amount of information is now available concerning the thermodynamic and kinetic properties of a number of alloys of potential interest for use as electrodes in elevated temperature lithium battery systems. Several of these have been found to have quite rapid kinetics and attractive capacities, with relatively small voltage losses and weight penalties.

In addition, recent results have extended these results down to ambient temperatures, indicating that some such materials may be of interest for use with new low temperature molten salt electrolytes, or with organic solvent electrolytes.

The all-solid mixed-conductor matrix concept will also be reviewed briefly. In this approach, the thermodynamic behavior of two different binary alloy systems can be combined to produce dense all-solid electrodes that have the kinetic properties of fine particle dispersions, as well as potentially attractive microstructural reversibility upon cycling.

\section{INTRODUCTION}

The cycling behavior of electrochemical cells, especially at lower temperatures, is often limited by negative electrode problems. These may include gradually increasing impedance, which is observed as increased electrode overvoltage. In some cases, there is macroscopic shape change. If elemental electrodes are used (below their melting points), there may be 
dendrite growth, or a tendency for filamentary or whisker growth. This may lead to disconnection and electrical isolation of active material, resulting in loss of capacity. It may also result in electrical shorting between electrodes.

In the absence of a significant nucleation barrier, deposition of a species will tend to occur anywhere at which the electric potential is such that the element's chemical potential is at or above that corresponding to unit activity. This means that electrodeposition may take place upon current collectors and other parts of an electrochemical cell that are at the same potential as the negative electrode, as well as upon the electrode structure where it is actually desired. This was a significant problem during the period in which attempts were being made to use pure (molten) lithium as the negative electrode in high temperature molten salt cells. Another problem was the fact that alkali metals dissolve in their halides at elevated temperatures, leading to electronic conduction and self discharge.

In addition to these problems, the electrodeposition of a pure elemental negative electrode upon recharge can be inherently unstable on a microscopic scale, even in the presence of a chemically clean interface. It has been shown that electrodeposition can lead to an electrochemical analog of the constitutional supercooling that occurs during thermally-driven solidification (ref. 1,2 ). This will be the case if the current density is such that solute depletion in the electrolyte near the electrode surface causes the local gradient of the element's chemical potential in the electrolyte immediately adjacent to the solid surface to be positive. Under such a condition, there will be a tendency for any protuberance upon the surface to grow at a faster rate than the rest of the interface. This leads to exaggerated surface roughness, and eventually to the formation of stable dendrites. In more extreme cases, it leads to the nucleation of solid particles in the liquid electrolyte ahead of the growing solid interface.

Further, the interface between the negative electrode and the adjacent electrolyte is often not clean. Instead, reaction between the electrode and species in the electrolyte can lead to the formation of reaction product layers. The properties of these layers can have significant effects upon the resultant behavior of the electrode. In some cases they may be useful solid electrolytes, and allow electrodeposition through them. But in many others they are ionically blocking, and thus can greatly increase the interfacial impedance. The presence of such layers, and the local nature of their electrical breakdown, generally related to defects in their structure that lead to spots of locally reduced impedance, often causes the formation of deleterious filamentary growths upon recharge. This is an endemic problem with the use of organic solvent electrolytes with lithium electrodes at ambient temperatures.

These problems can often be alleviated by the use of alloys, instead of elements, as negative electrode reactants. If the diffusion of the depositing species, e.g. Li, in the alloy is sufficiently fast that the activity at the surface remains less than unity, dendrite formation can be avoided. Deposition also occurs preferentially upon the desired electrode structure, rather than at other locations in the cell. In favorable cases, the formation of deleterious surface films may also be avoided. 
However, the use of alloys with reduced activities implies reduced cell voltages, as well as increased weight. Therefore, possible increases in reversibility and cycle life of such electrodes are accompanied by reductions in the associated specific energy and energy density of cells in which they are employed.

Another potential problem in the use of alloy electrodes relates to the fact that there may be a significant volume or shape change involved in the electrode reaction. In some cases this will lead to mechanical deterioration of the electrode structure. In other cases, it is negligible.

\section{EXPERIMENTAL RESULTS}

A number of investigations have now been completed which have established the theoretical basis for understanding and predicting the potentials and capacities of both binary and ternary lithium alloys. These important practical parameters are directly related to the thermodynamic properties and compositional ranges of the pertinent phases in the respective phase diagrams.

In addition, measurements have been made of the chemical diffusion coefficient, which controls the kinetic behavior, in intermediate phases in a group of lithium alloy systems. Some of these have crystal structures that result in very high rates of lithium diffusion, indicating that they are good candidates for high rate cells.

There are three different types of reactions that can occur in electrodes, formation reactions, displacement reactions, and insertion reactions. In the first two of these, the number of phases present is equal to the number of components (under isothermal and isobaric conditions), so that, according to the Gibbs Phase Rule, all of the intensive parameters are independent of overall composition. This means that the electrode potential, under equilibrium or near-equilibrium conditions, is essentially constant. This leads to generally-desirable plateaus in discharge curves.

The length of these plateaus is determined by the extent of the two-phase regions in the related phase diagrams, in the case of binary alloys. In the ternary case, it is determined by the width of the three-phase constant-potential triangles.

\section{Thermodynamic Data}

Whereas, as pointed out above, it is possible to have insertion reactions in alloys, it has been found that these do not generally extend over appreciable compositional ranges in lithium-based alloy systems. For this reason, as well as the fact that such solid solution reactions produce potentials that vary with composition, rather than exhibiting constant voltage plateaus, the bulk of the work to date has focussed upon materials that undergo displacement reactions.

An experimental arrangement employing the LiCl-KCl eutectic molten salt has been used in our laboratory at temperatures near $400{ }^{\circ} \mathrm{C}$ to study the phase diagrams and thermodynamic properties of alloys in the Li-Al, Li-Si, Li-Sb, 
$\mathrm{Li}-\mathrm{Bi}, \mathrm{Li}-\mathrm{Sn}, \mathrm{Li}-\mathrm{Pb}, \mathrm{Li}-\mathrm{In}, \mathrm{Li}-\mathrm{Ga}$ and Li-Cd binary systems. The equilibrium potentials, as well as the stoichiometric ranges over which they are found, are presented in Table $I$.

More recently, attention has been turned to the evaluation of such properties at lower temperatures. This has involved measurements (ref. 3) using $\mathrm{LiNO}_{3}-\mathrm{KNO}_{3}$ molten salts at about $150{ }^{\circ} \mathrm{C}$, as well as experiments with organic solvent-based electrolytes at ambient temperatures (ref.4,5).

Coulometric titration data were obtained over this wide temperature range for two alloy systems, $\mathrm{Li}-\mathrm{Sb}$ and $\mathrm{Li}-\mathrm{Bi}$, each of which have two intermediate phases, in order to illustrate relevant principles. The temperature dependence of the potentials of the two - phase equilibria in the Li-Sb system fell upon two straight lines, corresponding to the reactions $2 \mathrm{Li}+\mathrm{Sb}=\mathrm{Li}_{2} \mathrm{Sb}$ and $\mathrm{Li}+$ $\mathrm{Li}{ }_{2} \mathrm{Sb}=\mathrm{Li} \mathrm{i}_{3} \mathrm{Sb}$, where $\mathrm{Sb}$ indicates the lithium-saturated terminal phase.

In the $\mathrm{Li}-\mathrm{Bi}$ case, however, where the comparable reactions are $\mathrm{Li}+\mathrm{Bi}=$ $\mathrm{LiBi}$ and $2 \mathrm{Li}+\mathrm{LiBi}=\mathrm{Li}_{3} \mathrm{Bi}$, the temperature dependence is different. The data for the two reactions converge at high temperatures. Above about $420{ }^{\circ} \mathrm{C}$, the phase $\mathrm{LiBi}$ is no longer stable, and there is only a single reaction, $3 \mathrm{Li}$ $+\mathrm{Bi}=\mathrm{Li}_{3} \mathrm{Bi}$.

In addition, the potentials of the second reaction fall along two straight line segments, depending upon the temperature range. There is a significant change in slope at about $210^{\circ} \mathrm{C}$, resulting in a negligible temperature dependence of the potential at low temperatures, due to the melting of bismuth.

From these temperature dependences, one can obtain values of the molar entropies of these several reactions. They are given in Table II.

In addition to the investigations at elevated temperatures, attention has been given to the ambient temperature properties of several alloy systems. Data on the potentials and stoichiometric ranges of the plateaus in the Li-Sb, $\mathrm{Li}-\mathrm{Bi}, \mathrm{Li}-\mathrm{Sn}, \mathrm{Li}-\mathrm{Pb}, \mathrm{Li}-\mathrm{Zn}$ and Li-Cd systems at $25^{\circ} \mathrm{C}$ are shown in Table III.

The Li-Cd system is especially interesting, for it has a long plateau, spanning about $1.5 \mathrm{Li}$ per mole, at a potential only about $50 \mathrm{mV}$ above pure lithium.

\section{Kinetic Data}

As mentioned above, the kinetic properties of alloy electrodes are often determined by the rate at which solid state diffusion can occur through the outer phase of a two-phase microstructure. The pertinent basic parameter here is the chemical diffusion coefficient.

Several techniques have been developed whereby precise and reliable values of the chemical diffusion coefficient can be obtained by the use of molten salt electrochemical cell techniques (ref. 6-10). The physical arrangement can be closely related to that used for the thermodynamic measurements mentioned above. 
The principles underlying the application of use of transient or relaxation electrochemical methods for the determination of the chemical diffusion coefficient in solids have been reviewed in a number of the places cited above, and thus will not be discussed here. One of the especially attractive features of this approach, compared to conventional methods, is the relative ease with which one can obtain data of high precision.

In addition to these methods, it was shown a few years ago (ref.10-14) that a steady state ac method can also be used to obtain chemical diffusion data.

By the use of a combination of kinetic measurements and coulometric titration, which provides great compositional resolution, the variation of the diffusion coefficient with composition within phases, even if they have very narrow ranges of composition, can be readily obtained. This is particularly important in understanding the kinetics of polyphase electrode reactions.

As pointed out by Carl Wagner in an important paper (ref.15) in 1953, the chemical diffusion coefficient can be very much greater than the self diffusion coefficient in some materials. It is the latter quantity that has generally been measured in conventional radiotracer studies of diffusion in metals and alloys. This relationship is simply $D_{c}=D_{S} \cdot W$, where the quantity $W$ is an enhancement factor, which can be written $w=d \ln a_{i} / d \ln c_{i}$, where $a_{i}$ and $c_{i}$ are the activity and concentration of electrically neutral species $i$, respectively. This enhancement factor has been discussed by Wagner (ref.15,16), and was expressed in a somewhat different form by Darken (ref.17), who called it the "thermodynamic factor". A general discussion of this factor, and its evaluation under various conditions relevant to electrochemical systems appeared (ref.6) in 1977. By the use of the coulometric titration technique, the compositional variation of $\mathrm{W}$ can be experimentally determined.

These various techniques have been used to investigate chemical diffusion in a number of binary lithium alloys at elevated temperatures, and more recently, at ambient temperatures. Some of these data are included in Table IV. It can be seen that the value of $\mathrm{W}$ can be very large in some cases, and that this can lead to unusually high values of the chemical diffusion coefficient. This is indeed a fortunate circumstance, for it permits much faster electrode kinetics than would otherwise be the case.

\section{The Mixed-Conductor Matrix Concept}

In order to provide a high reactant surface area, and thus be able to achieve appreciable macroscopic current densities while maintaining low local microscopic charge and particle flux densities, many battery electrodes that are used in conjunction with liquid electrolytes are produced with porous microstructures containing very fine particles of the solid reactant materials. This porous structure is permeated with the electrolyte.

This porous fine-particle approach has several characteristic disadvantages. Among these are difficulties in producing uniform and reproducible microstructures, and limited mechanical strength when highly porous. In addition, they often suffer time-dependent changes in both microstructure and properties during cyclic operation. 
A quite different approach was introduced a few years ago (ref. 18-20), in which a dense solid electrode is fabricated which has a composite microstructure in which particles of the reactant phase are finely dispersed within a solid mixed-conducting metallic matrix. This provides a large internal reactant/matrix interfacial area. If the matrix material has a high chemical diffusion rate for the electroactive species it can be rapidly transported through the solid matrix to this interfacial region, where it undergoes the chemical part of the electrode reaction. If the matrix material is also an electronic conductor, it acts as the electrode's current collector, and the electrochemical part of the reaction takes place on the outer surface of the composite electrode.

Upon discharge of such an electrode by deletion of the electroactive species, if a residual reactant particle does not interact with the surrounding matrix, it remains as a relic in the microstructure. This provides a fixed permanent location for the reaction to take place during following cycles. This provides a mechanism for the achievement of true microstructural reversibility.

There are several features of this situation that serve to illustrate and expand upon some of the principles discussed above. There are both thermodynamic and kinetic requirements that must be met.

The matrix and the reactant phase must be thermodynamically stable in contact with each other. One can evaluate this possibility if one has information about the relevant phase diagram - which typically involves a ternary system - as well as the titration curves of the component binary systems. In a ternary system, two materials must lie at the corners of the same constant-potential tie triangle in the isothermal ternary phase diagram in order to not interact. The potential of the tie triangle determines the electrode reaction potential. Therefore, an additional requirement is that the reactant material have two phases present in the tie triangle, but the matrix phase only one. This is another way of saying that the stability window of the matrix phase must span the reaction potential, but that the binary titration curve of the reactant material has a plateau at the tie triangle potential. One can evaluate the possibility that these conditions are met from knowledge of the binary titration curves, without having to do a large number of ternary experiments.

The kinetic requirements for a successful application of these concepts are also understandable. The primary issue is the chemical diffusion rate of the electroactive species in the matrix phase. That can be determined by the various techniques discussed above.

An example has been demonstrated (ref.18-20) that meets all of these requirements, the use of the phase with the nominal composition $\mathrm{Li}_{13} \mathrm{Sn}_{5}$ as the matrix, in conjunction with reactant phases in the lithium-silicon system at temperatures near $400{ }^{\circ} \mathrm{C}$. This is an especially favorable case, due to the high chemical diffusion coefficient of lithium in the $\mathrm{Li}_{13} \mathrm{Sn}_{5}$ phase. There are surely other examples. We are currently investigating some possible combinations that might be useful at ambient temperatures in lithium systems.

One other obvious requirement is that the microstructure must have the ability to accommodate any volume changes that might result from the reaction 
that takes place internally. This can surely be taken care of by clever microstructural design and fabrication techniques.

\section{REFERENCES}

1. R. A. Huggins, J. Electrochem. Soc. 122, 90C (1975)

2. R. A. Huggins and D. Elwell, J. Crystal Growth 37, 159 (1977)

3. J. P. Doench and R. A. Huggins, J. Electrochem. Soc. 129, 341C (1982)

4. J. Wang, I. D. Raistrick and R. A. Huggins, J. Electrochem. Soc. 133, 457 (1986)

5. J. Wang, P. King and R. A. Huggins, Solid State Ionics 20, 185 (1986)

6. W. Weppner and R. A. Huggins, J. Electrochem. Soc. 124, 1569 (1977)

7. W. Weppner and R. A. Huggins, Z. f. Physik. Chem. NF 108, 105 (1977)

8. W. Weppner and R. A. Huggins, J. Solid State Chem. 22, 297 (1977)

9. W. Weppner and R. A. Huggins, in Annual Review of Materials Science, Vol 8, ed. by R. A. Huggins, Annual Reviews, Inc. (1978), p. 269

10. C. J. Wen, C. Ho, B. A. Boukamp, I. D. Raistrick, W. Weppner and R. A. Huggins, in International Metals Reviews 5,253 (1981)

11. R. A. Huggins, in Chemical Metallurgy - A Tribute to Carl Wagner, ed. by N. A. Gokcen, A.I.M.E. (1982), P. 149

12. B. A. Boukamp, I. D. Raistrick and R. A. Huggins, in East Ion Transport in Selids, ed. by P. Vashishta, J. N. Mundy and G. K. Shenoy, North-Holland (1979), p. 177

13. C. Ho, I. D. Raistrick and R. A. Huggins, J. Electrochem. Soc. 127, 343 (1980)

14. C. Ho, Ph.D. Dissertation, Stanford University (1980)

15. C. Wagner, J. Chemical Physics 21, 1819 (1953)

16. C. Wagner, in Atom Movements, American Society for Metals (1951), p. 153

17. L. S. Darken, Trans. A.I.M.E. 175, 184 (1948)

18. B. A. Boukamp, G. C. Lesh and R. A. Huggins, J. Electrochem. Soc. 128, 725 (1981)

19. B. A. Boukamp, G. C. Lesh and R. A. Huggins, in Proceedings of the Sympesium on Lithium Batteries, ed. by $H$. V. Venkatasetty, Electrochem. Soc. (1981), p. 467 
20. R. A. Huggins and B. A. Boukamp, U. S. Patent 4,436,796 (1984)

21. L. R. McCoy and S. Lai, in Proc. of Symposium and Workshop on Advanced Battery Research and Design, Argonne Nat'l Lab. ANL-76-8 (1976), p. B-167

22. S. Lai, J. Electrochem. Soc. 123, 1196 (1976)

23. R. A. Sharma and R. N. Seefurth, J. Electrochem. Soc. 123, 1763 (1976)

24. C. J. Wen and R. A. Huggins, J. Solid State Chem. 37, 271 (1981)

25. C. J. Wen, Ph.D. Dissertation, Stanford University (1980)

26. C. J. Wen and R. A. Huggins, Mat. Res. Bull. 15, 1225 (1980)

27. M. L. Saboungi, J.J. Marr, K. Anderson and D.R. Vissers, J. Electrochem. Soc. 126, 322C (1979)

28. C. J. Wen and R. A. Huggins, J. Electrochem. Soc. 128, 1636 (1981)

29. C. J. Wen and R. A. Huggins, J. Electrochem. Soc. 128, 1181 (1981)

30. C. J. Wen. B.A. Boukamp, R.A. Huggins and W. Weppner, J. Electrochem. Soc. 126,2258 (1979)

31. W. Weppner and R.A. Huggins, J. Electrochem. Soc. 125, 7 (1978)

32. W. Weppner and R. A. Huggins, J. Solid State Chem. 22, 297 (1977)

33. C. J. Wen and R. A. Huggins, J. Solid State Chem. 35, 376 (1980) 
Table I.

Thermodynamic Data For A Number of Binary Alloys

\begin{tabular}{|c|c|c|c|c|c|}
\hline $\begin{array}{l}\text { Voltage } \\
\text { vs. Li }\end{array}$ & system & Range & of $y$ & $\begin{array}{l}\text { Temp. } \\
\left({ }^{\circ} \mathrm{C}\right)\end{array}$ & Reference \\
\hline 0.047 & ${ }^{L} i_{Y} S i$ & $3.25-$ & -4.4 & 400 & $(21-24)$ \\
\hline 0.058 & $\mathrm{Li}_{\mathrm{Y}} \mathrm{Cd}$ & $1.65-$ & -2.33 & 400 & $(25)$ \\
\hline 0.080 & $\mathrm{Li}_{\mathrm{Y}} \mathrm{In}$ & 2.08 & -2.67 & 400 & $(26)$ \\
\hline 0.089 & $\mathrm{Li}_{\mathrm{Y}} \mathrm{Pb}$ & 3.8 & -4.4 & 400 & (27) \\
\hline 0.091 & $\mathrm{Li}_{Y} \mathrm{Ga}$ & $1.53-$ & -1.93 & 400 & (28) \\
\hline 0.122 & $\mathrm{Li}_{Y} \mathrm{Ga}$ & 1.28 & -1.48 & 400 & (28) \\
\hline 0.145 & $\mathrm{~L} i_{Y} \mathrm{In}$ & $1.74-$ & -1.92 & 400 & $(26)$ \\
\hline 0.156 & $L i_{Y} S i$ & $2.67-$ & -3.25 & 400 & $(21-24)$ \\
\hline 0.170 & $L i_{Y} S n$ & $3.5-$ & -4.4 & 400 & $(29)$ \\
\hline 0.237 & $\mathrm{Li}_{Y} \mathrm{~Pb}$ & $3.0-$ & -3.5 & 400 & (27) \\
\hline 0.271 & $\mathrm{Li}_{Y} \mathrm{~Pb}$ & $2.67-$ & -3.0 & 400 & $(27)$ \\
\hline 0.283 & $L i_{Y} S i$ & 2 & -2.67 & 400 & $(21-24)$ \\
\hline 0.283 & $\mathrm{Li}_{\mathrm{Y}} \mathrm{Sn}$ & 2.6 & -3.5 & 400 & $(29)$ \\
\hline 0.300 & $\mathrm{Li}_{Y} \mathrm{Al}$ & 0.08 & -0.9 & 400 & $(30)$ \\
\hline 0.332 & ${ }^{L} i_{Y} S i$ & 0 & -2 & 400 & $(21-24)$ \\
\hline 0.373 & $\mathrm{Li}_{y} \mathrm{Cd}$ & 0.33 & -0.45 & 400 & $(25)$ \\
\hline 0.375 & $\mathrm{Li}_{\mathrm{y}} \mathrm{Pb}$ & $1.1-$ & -2.67 & 400 & (27) \\
\hline 0.387 & $L i_{y} S n$ & 2.5 & -2.6 & 400 & (29) \\
\hline 0.430 & $\mathrm{Li}_{y} \mathrm{Sn}$ & 2.33 & -2.5 & 400 & (29) \\
\hline 0.455 & $\mathrm{Li}_{\mathrm{Y}} \mathrm{Sn}$ & $1.0-$ & -2.33 & 400 & (29) \\
\hline 0.495 & $\operatorname{Li}_{y} \operatorname{In}$ & 1.2 & -0.86 & 400 & $(26)$ \\
\hline 0.507 & $\mathrm{Li}_{\mathrm{y}} \mathrm{Pb}$ & 0 & -1.0 & 400 & (27) \\
\hline 0.558 & $L i_{y} C d$ & 0.12 & -0.21 & 400 & $(25)$ \\
\hline 0.565 & $\mathrm{Li}_{y} \mathrm{Ga}$ & 0.15 & -0.82 & 400 & $(28)$ \\
\hline 0.570 & $\mathrm{Li}{ }_{Y} \mathrm{Sn}$ & $0.57-$ & -1.0 & 400 & (29) \\
\hline 0.750 & $\mathrm{Li}_{y} \mathrm{Bi}$ & $1.0-$ & -2.82 & 400 & (31) \\
\hline 0.875 & $\mathrm{Li}_{\mathrm{y}} \mathrm{Sb}$ & 2.0 & -3.0 & 400 & (31) \\
\hline 0.910 & $L i_{y} S b$ & 0 & -2.0 & 400 & (31) \\
\hline
\end{tabular}


Table II.

Thermodynamic Data For The Li-Sb and Li-Bi systems

\begin{tabular}{|c|c|c|c|}
\hline Reaction & $\begin{array}{c}\text { Molar Entropy } \\
\text { of reaction } \\
\text { (J/K - mol) }\end{array}$ & Temp & $\begin{array}{l}\text { - range } \\
\left({ }^{\circ} \mathrm{C}\right)\end{array}$ \\
\hline $2 \mathrm{Li}+\mathrm{Sb}-->\mathrm{Li}_{2} \mathrm{Sb}$ & $-31 \cdot 9$ & 0 & -500 \\
\hline $\mathrm{Li}+\mathrm{Li}_{2} \mathrm{Sb} \rightarrow-\mathrm{Li}_{3} \mathrm{Sb}$ & -46.5 & 0 & -600 \\
\hline $\mathrm{Li}+\mathrm{Bi} \rightarrow->\mathrm{LiBi}$ & 0 & 0 & -200 \\
\hline $2 \mathrm{LI}+\mathrm{LiBi} \rightarrow \mathrm{Li}_{3} \mathrm{Bi}$ & -36.4 & 0 & -400 \\
\hline
\end{tabular}

Table III.

Plateau Potentials And Composition Ranges

in Lithium Alloys at Low Temperatures

\begin{tabular}{|c|c|c|c|c|c|}
\hline $\begin{array}{l}\text { Voltage } \\
\text { vs. Li }\end{array}$ & system & Rang & je of $y$ & $\begin{array}{l}\text { Temp. } \\
\left({ }^{\circ} \mathrm{C}\right)\end{array}$ & Reference \\
\hline 0.005 & $\operatorname{Li}_{y} \mathrm{Zn}$ & 1 & -1.5 & 25 & (5) \\
\hline 0.055 & $\mathrm{Li}_{y} \mathrm{Cd}$ & 1.5 & -2.9 & 25 & (5) \\
\hline 0.157 & $\mathrm{Li}_{\mathrm{y}}^{\mathrm{Zn}}$ & 0.67 & -1 & 25 & (5) \\
\hline 0.219 & $\mathrm{Li}_{\mathrm{y}} \mathrm{Zn}$ & 0.5 & -0.67 & 25 & (5) \\
\hline 0.256 & $\mathrm{Li}_{\mathrm{y}} \mathrm{Zn}$ & 0.4 & -0.5 & 25 & (5) \\
\hline 0.292 & $\mathrm{Li}_{y} \mathrm{~Pb}$ & 3.2 & -4.5 & 25 & (5) \\
\hline 0.352 & $\mathrm{Li}_{Y} \mathrm{Cd}$ & 0.3 & -0.6 & 25 & (5) \\
\hline 0.374 & $\mathrm{Li}_{\mathrm{y}} \mathrm{Pb}$ & 3.0 & -3.2 & 25 & (5) \\
\hline 0.380 & ${ }^{\mathrm{Li}}{ }_{Y} \mathrm{Sn}$ & 3.5 & -4.4 & 25 & (4) \\
\hline 0.420 & $\mathrm{Li}_{y} \mathrm{Sn}$ & 2.6 & -3.5 & 25 & (4) \\
\hline 0.449 & $\mathrm{Li}_{Y} \mathrm{~Pb}$ & 1 & -3.0 & 25 & (5) \\
\hline 0.485 & $\operatorname{Li}_{y} \operatorname{Sn}$ & 2.33 & -2.63 & 25 & (4) \\
\hline 0.530 & $\mathrm{Li}_{y} \mathrm{Sn}$ & 0.7 & -2.33 & 25 & (4) \\
\hline 0.601 & $\mathrm{Li}_{y} \mathrm{~Pb}$ & 0 & -1 & 25 & (5) \\
\hline 0.660 & $\mathrm{Li}_{Y} \mathrm{Sn}$ & 0.4 & -0.7 & 25 & (4) \\
\hline 0.680 & $\mathrm{Li}_{y} \mathrm{Cd}$ & 0 & -0.3 & 25 & (5) \\
\hline 0.810 & $\mathrm{Li}{ }_{y} \mathrm{Bi}$ & 1 & -3 & 25 & (4) \\
\hline 0.828 & $\mathrm{Li}_{y} \mathrm{Bi}$ & 0 & - & 25 & (4) \\
\hline 0.948 & $\mathrm{Li}_{\mathrm{y}} \mathrm{Sb}$ & 2 & - & 25 & (4) \\
\hline 0.956 & $\mathrm{Li}_{y} \mathrm{sb}$ & 1 & -2 & 25 & (4) \\
\hline
\end{tabular}


Table IV

Data On Chemical Diffusion in Lithium Alloy Phases

\begin{tabular}{llllll}
$\begin{array}{l}\text { Nominal } \\
\text { Comp. }\end{array}$ & $\begin{array}{l}\text { Range of } \\
\text { Composition } \\
(8 \mathrm{Li})\end{array}$ & $\begin{array}{c}\text { Max. Value } \\
\text { of } \mathrm{D}_{\mathrm{C}} \\
\left(\mathrm{cm}^{2} / \mathrm{sec}\right)\end{array}$ & $\begin{array}{c}\text { Max. Value } \\
\text { of } \mathrm{W}\end{array}$ & $\begin{array}{c}\text { Temp } \\
\left({ }^{\circ} \mathrm{C}\right)\end{array}$ & Reference \\
\hline $\mathrm{LiAl}$ & 16.4 & $1.2 \times 10^{-4}$ & 70 & 415 & 10,30 \\
$\mathrm{Li}{ }_{3} \mathrm{Sb}$ & 0.05 & $7.0 \times 10^{-5}$ & 70000 & 360 & 6 \\
$\mathrm{Li}_{3} \mathrm{Bi}$ & 1.37 & $2.0 \times 10^{-4}$ & 370 & 380 & 32 \\
$\mathrm{Li}_{12} \mathrm{Si}_{7}$ & 0.54 & $8.1 \times 10^{-5}$ & 160 & 415 & 24 \\
$\mathrm{Li}_{7} \mathrm{Si}_{3}$ & 3.0 & $4.4 \times 10^{-5}$ & 111 & 415 & 24 \\
$\mathrm{Li}_{13} \mathrm{Si}_{4}$ & 1.0 & $9.3 \times 10^{-5}$ & 325 & 415 & 24 \\
$\mathrm{Li}_{22} \mathrm{Si}_{5}$ & 0.4 & $7.2 \times 10^{-5}$ & 232 & 415 & 24 \\
$\mathrm{LiSn}_{\mathrm{Li}} \mathrm{Sn}_{3}$ & 1.9 & $4.1 \times 10^{-6}$ & 185 & 415 & 33 \\
$\mathrm{Li}_{5} \mathrm{Sn}_{2}$ & 0.5 & $4.1 \times 10^{-5}$ & 110 & 415 & 33 \\
$\mathrm{Li}_{13} \mathrm{Sn}_{5}$ & 1.0 & $5.9 \times 10^{-5}$ & 99 & 415 & 33 \\
$\mathrm{Li}_{7} \mathrm{Sn}_{2}$ & 1.4 & $7.6 \times 10^{-4}$ & 1150 & 415 & 33 \\
$\mathrm{Li}_{22} \mathrm{Sn}_{5}$ & 1.2 & $7.8 \times 10^{-5}$ & 196 & 415 & 33 \\
$\mathrm{LiGa}_{\mathrm{Li} \mathrm{In}}$ & 22.0 & $1.9 \times 10^{-4}$ & 335 & 415 & 33 \\
$\mathrm{LiCd}^{3}$ & 63.0 & $6.8 \times 10^{-5}$ & 56 & 415 & 28 \\
$\mathrm{Li}_{3} \mathrm{Sn}_{4}$ & & $4.0 \times 10^{-5}$ & 52 & 415 & 26 \\
$\mathrm{Li}_{7} \mathrm{Sn}_{3}$ & & $3.0 \times 10^{-6}$ & 7 & 415 & 25 \\
\end{tabular}

